\title{
INDEKS PERSEPSI KORUPSI DITINJAU DARI IQ NASIONAL DAN GDP DI ASIA TENGGARA
}

\author{
Satrio Budi Wibowo \\ Universitas Muhammadiyah Metro \\ E-Mail: satrio-budi@mail.ugm.ac.id
}

\begin{abstract}
Intisari: Saat ini, hasil tes kecerdasan (IQ) tidak hanya digunakan untuk melihat variasi kecerdasan secara invidual, tapi mulai digunakan untuk melihat variasi kecerdasan secara kelompok bahkan negara. Richard Lynn dan Tatu Vanhanen's merupakan peneliti pertama yang menggunakan IQ nasional sebagai variabel penelitian, yang kemudian berkembang dan banyak di teliti. Peneliti tertarik mencoba melihat keterkaitan variasi IQ nasional, Gross Domestic Product (GDP), dan Indeks Persepsi Korupsi antara beberapa negara di Asia Tenggara. Hasil penelitian yang dilakukan pada tujuh negara Asia Tenggara didapatkan korelasi yang singnifikan antara IQ nasional dengan GDP dan IQ nasional dengan Indeks Persepsi Korupsi.
\end{abstract}

\section{PENDAHULUAN}

Defenisi tentang pengertian intelegensi telah ramai diperdebatkan sejak zaman yunani kuno hingga saat ini (Gardner, 1996). Socrates dan para filosof Yunani lainnya sudah mulai membahas tentang arti dari intelegensi, misalnya Socrates yang mengatakan bahwa orang yang cerdas adalah orang yang paling bijak (Gardner, 1996). Para ahli psikologi barat mulai mendefenisikan intelegensi sebagai kemampuan untuk memecahkan masalah yang bersifat abstrak (Sternberg, 1990; Gardner, 1996). Setelah didefenisikan, kemudian para ahlipun berupaya untuk membuat alat ukur yang tepat untuk mengukur intelegensi. Terman, merupakan orang yang pertama kali mendesain test terstandar berdasar pada defenisi intelegensi sebagai kemampuan untuk memecahkan masalah yang bersifat abstrak (Gardner, 1996).

Intelegensi merupakan representasi dari kemampuan potensial kognitif individu. Hasil tes intelegensi biasanya dilaporkan sebgai hasil kemampuan satu individu saja. Hasil tes intelegensi individual, dalam penelitian berguna untuk melihat apakah variasi intelegensi secara individual berpengaruh terhadap variasi pada variabel lain secara individual, misalnya melihat pengaruh intelegensi terhadap prestasi belajar siswa. Sehingga banyak ditemukan berbagai judul penelitian yang mengunakan variabel intelegensi untuk diteliti dengan berbagai variabel lain, akan tetapi hal ini mengacu pada variasi individual.

Baru-baru ini hasil tes intelegensi (IQ) sudah mulai dilaporkan untuk mewakili kapasitas kecerdasan suatu kelompok. Salah satunya adalah IQ Nasional (Shatz, 2007). IQ nasional menggambarkan variasi nilai 
intelegensi antar Negara, dimana IQ nasional ini digunakan untuk melihat kapasitas IQ rata-rata populasi pada suatu Negara.

IQ nasional didapatkan melalui pengukuran dengan menggunakan tes Raven's Progressive Matrices (RPM), tes penalaran non-verbal atau diukur dengan berbagai variasi alat ukur non-verbal lainnya, termasuk The Cattell Culture Fair dan the Goodenough Draw-a-Person test (Lynn, Meisenberg, Mikk, \& Williams, A., 2007). Penggunaan tes non verbal untuk mengukur IQ nasional ditujukan agar hasil tes, bebas budaya (Lynn, dkk. 2007). Pengukuran IQ secara nasional dengan alat tes yang bebas budaya, ditujukan agar tes mampu merepresentasikan kemampuan intelegensi tiap Negara dengan adil, walaupun tiap Negara memiliki bahasa dan budaya yang berbeda.

Pengukuran IQ secara nasional menjadi prespektif baru dalam meneliti intelegensi lebih lanjut. Pengukuran IQ nasional pertama kali dilakukan oleh Richard Lynn dan Tatu Vanhanen's yang diutarakan dalam bukunya "IQ and the Wealth of Nations" (Kanazawa, 2006). Lynn dan Vanhanen (2002) memperlihatkan bahwa tingkat intelegensi bervariasi sangat besar diantara negara-negara. Lynn dan Vanhanen dalam studi pertama mereka, mempresentasikan hasil kompilasi dari 81 negara dan melaporkan rata-rata nilai IQ ke - 81 negara berkisar antara 59-107, dimana yang terendah adalah negara di Equatorial Guinea dan tertinggi adalah Hongkong. Kemudian jumlah Negara yang di tes bertambah menjadi 98 negara. Pada studi kedua Lynn dan Vanhanen, mereka memperluas jumlah Negara dengan mengukur IQ 113 negara, dan memberikan perkiraan bagi 79 negara tambahan.

Sejak publikasi dari Lynn dan Vanhanen's pada tahun 2002, IQ nasional mulai dijadikan sebagai sebuah variabel dan digunakan dalam banyak penelitian. Hasil-hasil penelitian menunjukkan bahwa IQ nasional ditemukan memiliki korelasi yang erat dengan tingkat kekayaan negara (Lynn, dkk. 2007), pertumbuhan ekonomi (Weede \& Kämpf, 2002), sistem nilai budaya (Meisenberg, 2004) dan bunuh diri (Voracek, 2004). Barber (dalam Shatz, 2007) melaporkan hubungan IQ nasional dengan berbagai macam variabel demografis nasional seperti, dengan proporsi pekerja yang bermata pencarian petani $(r=-0.70)$, proporsi berat kelahiran bayi yang rendah $(r=-0.48)$, rata-rata buta huruf $(r=-0.71)$, rata-rata kematian bayi $(r=-0.34)$, rasio pendaftaran ke sekolah lanjutan $(\mathrm{r}=0.72)$ dan Vanhanen (2004) menemukan korelasi dengan Grosss National product (GNP) ( $r=0.54)$. Hasil hasil penelitian menunjukkan bahwa inteligensi muncul sebagai komponen utama dari 'human development', dan sebuah determinan dari banyak budaya dan perbedaan ekonomi diantara Negara (Vanhanen, 2004).

Keterkaitan IQ dengan beberapa indikator ekonomi, pendidikan, nilai budaya bahkan dengan bunuh diri, menarik perhatian penulis untuk meneliti lebih lanjut keterkaitan IQ nasional dengan indikator lainnya, yaitu dengan Gross Domestic Product (GDP) dan tingkat korupsi. Untuk lebih fokus serta dikarenakan keterbatasan data, maka korelasi antara IQ nasional, GDP dan indeks korupsi akan dilakukan pada lingkup Asia Tenggara.

Negara - negara Asia Tenggara terdiri atas 11 Negara : Brunei Darussalam, Kamboja, Indonesia, Laos, Timor leste, Malaysia, Myanmar, Filipina, Singapura, Thailand dan Vietnam. Namun, dalam penelitian ini, peneliti hanya mengambil 7 negara Asia Tenggara saja, yaitu, Indonesia, Malaysia, Myanmar, Philippines, Singapura, Thailand dan Vietnam. Hal ini disebabkan dikarenakan keterbatasan data yang didapatkan, sehingga hanya 7 
38 | Indeks Persepsi Korupsi

negara Asia Tenggara yang diikutkan dalam analisis. Tujuh negara Asia Tenggara yang diikutkan diharapkan dapat merepresentasikan keterkaitan IQ nasional, GDP dan indeks korupsi di kawasan Asia Tenggara.

Berbicara mengenai korupsi menjadi menarik, apalagi di antara negara-negara Asia Tenggara, lebih khususnya Indonesia. Saat ini korupsi merupakan problem yang serius di banyak negara Asia (Quah, 2003). United Nations Development Programme (UNDP) telah mendefenisikan korupsi sebagai "Penyalahgunaan kekuasaan publik, kantor atau kewenangan untuk kepentingan pribadi - melalui penyuapan, pemerasan, menyalahgunakan pengaruh, nepotisme, penggelapan " (Quah, 2003). Sayangya, korupsi yang terjadi di negeranegara Asia Tenggara belum ditangani secara serius, dan bahkan masih dianggab sebagai tabu yang tidak pantas untuk dibicarakan atau bahkan diteliti (Quah, 2003).

Mulai tahun 1995 Transparency International (TI) mengeluarkan indeks persepsi korupsi. 7 negara Asia Tenggara yang diteliti juga masuk dalam daftar indeks persepsi korupsi yang dilaporkan oleh Transparency International (TI). Singapura dari tahun ke tahun, menjadi negara urutan paling atas yang dipersepsikan lebih bebas korupsi dibandingkan negara-negara tetangganya di Asia Tenggara, sedangkan Indonesia dan Myanmar pada tahun 2003 berada pada peringkat paling dasar bila dibandingkan dengan negara-negara tetangganya di Asia Tenggara. Variasi indeks korupsi antara teratas yaitu Singapura dengan negara terbawah yaitu Indonesia dan Myanmar sangat besar, dari tahun ke tahun. Perbedaan indeks yang besar di antara negara Asia tenggara ini menjadi menarik untuk dilihat apakah memiliki korelasi yang signifikan terhadap variasi IQ nasional di antara negara - negara Asia Tenggara.

Gross Domestic Product (GDP) didefenisikan sebagai sebuah ukuran keseluruhan dari produksi total ekonomi sebuah negara, GDP mencerminkan nilai pasar untuk semua barang dan jasa yang diproduksi oleh ekonomi untuk suatu periode tertentu (Mahadana Learning, 2008). Dengan demikian dapat disimpulkan bahwa GDP merupakan Indikator makro ekonomi utama dalam sebuah negara. Indeks GDP di antara negara - negara Asia Tenggara pun bervariasi dan tidak merata. Beberapa negara memiliki indeks GDP yang sangat tinggi bahkan hampir menyamai beberapa negara maju, sedangkan beberapa negara lainnya memiliki indeks GDP yang sangat rendah bila dibandingkan negara-negara lain di kawasan Asia Tenggara. Variasi indeks GDP yang tidak merata di antara negara Asia Tenggara, juga menarik untuk di lihat lebih lanjut apakah memiliki korelasi dengan variasi IQ nasional di antara negara-negara Asia Tenggara.

Berdasarkan uraian di atas maka penelitian ini akan mengfokuskan penelitian untuk melihat apakah GDP berkorelasi dengan nilai IQ secara nasional di antara negara-negara Asia Tenggara, dan apakah IQ nasional berkorelasi dengan indeks persepsi korupsi antara negara-negara Asia Tenggara.

\section{TINJAUAN PUSTAKA}

\section{Intelegensi}

Intelegensi dapat didefenisikan sebagai kemampuan untuk memecahkan masalah yang bersifat abstrak (Stternberg, 1986, 1990; Gardner, 1996). Passer \& Smith (2007), menambahkan bahwa inteligensi merupakan kemampuan memperoleh pengetahuan, berpikir dan kemampuan memberikan alasan dengan efektif dan bisa 
beradaptasi dengan lingkungannya. Dalam memahami hakikat inteligensi, salah satu pendekatan umumnya adalah dengan pendekatan psikometri.

Pendekatan psikometri menilai kecerdasan manusia dengan sistem standarisasi, melalui pengukuran dengan alat tertentu. Para ahli psikometri berpendapat bahwa inteligensi sebagai kemampuan umum, yang pertama kali dikembangkan oleh Charles Spearman (Passer \& Smith, 2007). Menurut Spearman (dalam Sternberg, 2008), inteligensi sebagai suatu kemampuan umum yang merupakan satu kesatuan. Spearman menemukan bahwa perilaku manusia dipengaruhi oleh dua faktor, yaitu faktor umum (general factor) atau faktor $\mathrm{g}$ dan faktor khusus (special factor) atau faktor s. Faktor umum mendorong performa semua tes, faktor khusus berpengaruh pada tipe-tipe tertentu tes kemampuan (Sternberg, 2008). Spearman meyakini bahwa faktor umum, mendasari faktor-faktor khusus. Menurut Spearman, orang yang memiliki inteligensi tinggi adalah orang yang memiliki banyak sekali faktor umum, ia pintar matematika, fisika, kimia, mahir mengendarai mobil, menjadi atlet berprestasi, bahkan mampu mengemudikan pesawat terbang. Faktor umum tergantung pada dasar atau keturunan sedangkan faktor khusus dipengaruhi oleh pengalaman atau lingkungan (Suryabrata, 2000).

Selanjutnya Raymond Cattell (dalam Eggen \& Kauchak, 1997), mengatakan bahwa faktor g atau inteligensi umum ada dua, yaitu fluid intelligence dan crystalized intelligence. Fluid intelligence merupakan kekuatan dasar penalaran dan pemecahan problem, yang menghasilkan proses berfikir induktif, deduktif, dan pengertian tentang hubungan antar gagasan. Eggen \& Kauchak (1997) mengatakan bahwa fluid intelligence merefleksikan kemampuan umum dan kemampuan penyesuaian seseorang dalam menghadapi tugas-tugas baru. Crystalized intelligence adalah pengetahuan spesifik yang diperoleh individu sebagai hasil dari penerapan fluid intelligence (Bernstein, dkk., 1994). Oleh karena itu orang yang fluid intelligencenya tinggi sangat mungkin memiliki skor crystalized intelligence yang juga tinggi. Crystalized intelligence meliputi pengetahuan yang dimiliki dan kemampuan seseorang untuk mengases pengetahuan tersebut, yang diukur dengan tes kosa kata, berhitung, dan informasi umum.

IQ nasional merupakan nilai intelegensi yang didapatkan melalui pengukuran yang seringkali diukur dengan Raven's Progressive Matrices, tes penalaran non-verbal atau diukur dengan berbagai variasi alat ukur non-verbal lainnya, termasuk The Cattell Culture Fair dan the Goodenough Draw-a-Person test (Shatz, 2007). Tes Raven's Progressive Matrices mengukur inteligensi umum atau faktor $g$ berdasar konsepsi inteligensi dari Spearman. Tugas-tugas dalam The Advanced Progressive Matrices terdiri dari pola-pola abstrak yang bagiannya ada yang hilang. Testee diminta untuk menemukan bagian yang hilang dari setiap pola (aitem), dengan memilih satu alternatif yang sesuai dari delapan pilihan alternatif yang disediakan.

Hasil IQ nasional dari pengukuran yang dilakukan oleh Lynn \& Vanhanen (dalam Lynn, Meisenberg, Mikk \& Williams, 2007) pada tahun 2003 akan digunakan sebagai sumber data yang akan dianalisis lebih lanjut. Data IQ nasional berasal dari data tahun 2003, tidak up to date, karena penulis hanya mendapatkan data lengkap tentang IQ nasional di antara ketujuh Negara Asia Tenggara yang berasal dari tahun 2003. 
40 | Indeks Persepsi Korupsi

\section{Indeks persepsi korupsi / Corruption Perception Indeks (CPI)}

Indeks persepsi korupsi merupakan hasil pengukuran yang pertama kali dikeluarkan pada tahun 1995, yang dikenal baik sebagai alat Transparency International (TI). TI membentuk sebuah komite yang bernama Index Advisory Committee (IAC) pada tahun 1996 untuk memberikan masukan dengan alat ukur korupsi yang global. Anggota dari komite (anggota IAC) terdiri ahli ekonomi, statistik, dan ilmu sosial dan politik (Transparency International, 2003).

Indeks persepsi korupsi merupakan data yang menggambarkan tingkat peluang terjadinya korupsi $\mathrm{di}$ negara tertentu. Data dikumpulkan dari persepsi para pegusaha dan para ahli tentang kinerja pemerintah terutama berkaitan dengan pemberian layanan yang bebas korupsi. Data indeks persepsi korupsi yang dikeluarkan tiap tahun oleh TI dipercaya oleh banyak pihak sebagai data yang valid dalam mengukur praktek korupsi di suatu Negara (Transparency International, 2003). Data indeks persepsi korupsi yang akan digunakan dalam penelitian ini berasal dari Transparency International tahun 2003.

\section{Gross Domestic Product (GDP)}

Gross domestic product (GDP), merupakan nilai pasar dari semua barang dan jasa yang diproduksi oleh pekerja dan property yang berada di suatu daerah, yang biasanya disebut negara. GDP dapat juga didefenisikan sebagai sebuah ukuran keseluruhan dari produksi total ekonomi sebuah negara, GDP mencerminkan nilai pasar untuk semua barang dan jasa yang diproduksi di suatu Negara untuk suatu periode tertentu (Mahadana Learning, 2008).

Komponen GDP antara lain konsumsi personal, pembelian pemerintah, persediaan, dan neraca perdagangan (ekspor dan impor). GDP dirilis per kuartal, yang seringkali ditampilkan dalam basis persentase tahunan. Mayoritas data yang ditampilkan dalam indikator yang telah mengalami penyesuaian terhadap perubahan harga (Mahadana Learning, 2008). Indikator GDP merupakan sebuah laporan yang sangat komprehensif dan detail. Penjualan ritel, konsumsi personal, dan persediaan grosir, kesemuanya digunakan untuk menghitung GDP (Mahadana Learning, 2008).

Maka dapat disimpulkan bahwa GDP merupakan salah satu indikator dari keberhasilan ekonomi suatu Negara. Negara yang baik tingkat ekonominya diindikasikan dengan tingginya tingkat GDP. Sama seperti IQ nasional dan indeks persepsi korupsi, data mengenai GDP diambil berdasarkan data GDP tahun 2003 yang dipublikasikan oleh Rao, Jani \& Sanjivee (2007).

\section{Kerangka Hipotesis}

Bila dilihat bahwa IQ nasional berkaitan dengan tingkat kekayaan negara (Lynn \& Vanhanen, 2006; dalam Lynn, Meisenberg, Mikk \& Williams, 2007), pertumbuhan ekonomi (Weede \& Kämpf, 2002 dalam Lynn, Meisenberg, Mikk \& Williams, 2007), maka dapat diasumsikan bahwa IQ nasional ketujuh negara Asia Tenggara akan berkorelasi dengan GDPnya, karena GDP juga merupakan salah satu indikator dari pertumbuhan ekonomi. Sedangkan keterkaitan IQ nasional dengan indeks persepsi korupsi sepengetahuan penulis belum pernah di 
teliti, sehingga penulis tertarik untuk mencoba melihat hubungan antar IQ nasional dengan Indeks Persepsi Korupsi.

Konstrak hipotetis yang diajukan dalam tulisan ini,menempatkan IQ nasional sebagai variabel central yang akan dilihat kaitannya dengan GDP dan Indeks Korupsi. Konstrak hipotetis yang diajukan oleh peneliti dapat dilihat pada bagan berikut ini :

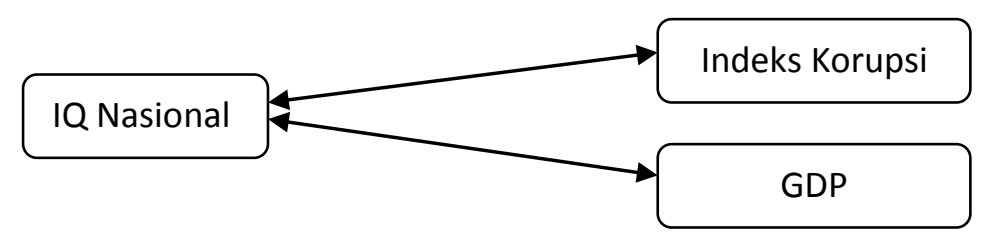

Gambar 1. Keterkaitan antara IQ Nasional dengan GDP dan Indeks Persepsi Korupsi

\section{METODE}

Sampel negara Asia Tenggara yang akan dijadikan sebagai subyek dalam penelitian ini terdiri dari negara Indonesia, Malaysia, Myanmar, Philippines, Singapura, Thailand dan Vietnam. Tujuh sampel negara Asia tenggara cukup untuk mewakili populasi negara Asia Tenggara yang hanya terdiri dari 11 negara, dimana secara proporsi ketujuh negara mewakili $63,3 \%$ dari keseluruhan jumlah populasi. Ketujuh negara dipilih tidak secara random, keikutsertaan negara menjadi sampel didasarkan atas kelengkapan data GDP, indeks persepsi korupsi dan IQ nasional yang tersedia hanya pada tujuh negara Asia Tenggara tersebut.

Data IQ nasional diambil dari perhitungan yang dilakukan oleh Lynn \& Vanhanen (2006). IQ nasional di hitung dengan Raven's Progressive Matrices, tes penalaran non-verbal, Cattell Culture Fair dan the Goodenough Draw-a-Person test. Data yang didapatkan tidak sepenuhnya setara, tetapi di banyak kasus, hasilnya mampu merepresentasikan sampel populasi dan masih dalam kontek tes nasional yang terstandarisasi. Data yang diambil hanya berasal dari 7 negara Asia Tenggara, hal ini dikarenakan peneliti hanya mampu mendapatkan data 7 negara Asia Tenggara. Data yang diambil adalah data tahun 2003. Data dari IQ nasional dapat dilihat pada tabel beikut.

Tabel 1. Data nilai Nasional IQ

\begin{tabular}{|l|l|c|}
\hline No & Negara & IQ Nasional \\
\hline 1 & Singapura & 108 \\
\hline 2 & Malaysia & 92 \\
\hline 3 & Thailand & 91 \\
\hline 4 & Filipina & 86 \\
\hline 5 & Vietnam & 94 \\
\hline 6 & Indonesia & 87 \\
\hline 7 & Myanmar & 87 \\
\hline
\end{tabular}

Lynn, Meisenberg, Mikk \& Williams (2007)

Pada studi ini, GDP perkapita (GDP) didapatkan dari data yang disajikan oleh Rao, Jani \& Sanjivee (2008). Komponen GDP antara lain konsumsi personal, pembelian pemerintah, persediaan, dan neraca 
42 | Indeks Persepsi Korupsi

perdagangan (ekspor dan impor). Data GDP ketujuh negara ASIA TENGGARA dapat dilihat dari pada tabel berikut.

Tabel 2. GDP Ketujuh Negara Asia Tenggara

\begin{tabular}{|l|l|l|}
\hline No & Negara & GDP \\
\hline 1 & Singapura & 28.08 \\
\hline 2 & Malaysia & 10.28 \\
\hline 3 & Thailand & 8.09 \\
\hline 4 & Filipina & 4.61 \\
\hline 5 & Vietnam & 2.75 \\
\hline 6 & Indonesia & 3.61 \\
\hline 7 & Myanmar & 1.03 \\
\hline
\end{tabular}

Rao, Jani \& Sanjivee (2008)

Data mengenai Indeks persepsi korupsi didapatkan dari hasil pengukuran yang dilakukan oleh transparency internasional. Semakin rendah skor indeks suatu Negara, mengindikasikan semakin buruk korupsi yang terjadi, sedangkan semakin tinggi nilai indeks persepsi korupsi menandakan semakin Negara tersebut bersih dari korupsi. Indeks persepsi korupsi tahun 2003 yang didapatkan dari transparency internasional dapat dilihat sebagai berikut.

Tabel 3. Indeks persepsi korupsi Ketujuh Negara Asia Tenggara.

\begin{tabular}{|l|l|l|}
\hline No & Negara & Indesk Korusi \\
\hline 1 & Singapura & 9.4 \\
\hline 2 & Malaysia & 5.2 \\
\hline 3 & Thailand & 3.3 \\
\hline 4 & Filipina & 2.5 \\
\hline 5 & Vietnam & 2,4 \\
\hline 6 & Indonesia & 1.9 \\
\hline 7 & Myanmar & 1.6 \\
\hline
\end{tabular}

(Taransparency International, 2003)

Data yang didapatkan kemudian akan dianalisis lebih lanjut dengan menggunakan rumus korelasi product moment dari Pearson. Teknik korelasi digunakan untuk melihat hubungan antara variabel IQ nasional dengan GDP dan hubungan antara IQ nasional dengan indeks persepsi korupsi.

\section{HASIL DAN PEMBAHASAN}

Berdasarkan hasil perhitungan IQ Nasional 2003 didapatkan skor IQ Nasional Indonesia sebesar 87, merupakan urutan keenam dari tujuh Negara Asia Tenggara yang dibandingkan, GDP Indonesia pada tahun 2003 didapatkan sebesar 3,61, merupakan urutan kelima diantara tujuh negara Asia Tenggara yang dibandingkan, sedakan indeks persepsi korupsi Indonesia pada tahun 2003 didapatkan skor sebesar 1,9 merupakan urutan keenam dari tujuh negara Asia Tenggara yang dibandingkan. Hasil perhitungan IQ nasional, GDP serta indeks persepsi korupsi, ternyata hampir selalu menempatkan Indonesia pada urutan terakhir. Hal ini mengindikasikan bahwa posisi Indonesia baik dari segi IQ nasional, GDP ataupun indeks persepsi korupsi pada tahun 2003 termasuk sangat buruk. 
Untuk melihat keterkaitan antara variabel IQ nasional, GDP dan Indesk Korupsi di antara ketujuh negara Asia Tenggara, maka peneliti menggunakan analisis korelasi sederhana. Hasil analisis yang didapatkan menunjukkan terdapat korelasi yang tinggi diantara variabel IQ nasional, GDP dan Indesk Korupsi di antara ketujuh negara Asia Tenggara.

Besarnya nilai korelasi antara GDP dan IQ Nasional didapatkan nilai koefisien korelasi sebesar $r=0,917$ $(p<0,01)$ dengan sumbangan efektif antar varian sebesar $84,1 \%\left(\mathrm{r}^{2}=0,841\right)$. Hasil ini mengidikasikan bahwa terdapat hubungan yang sangat erat antara IQ nasional dengan GDP, semakin tinggi IQ nasional suatu negara akan diikuti dengan semakin tingginya GDP negara tersebut. Hasil ini menguatkan hasil penelitan terdahulu bahwa IQ nasional berhubungan positif dengan indikator ekonomi suatu negara.

Adanya korelasi yang signifikan antara IQ nasional dengan GDP maka dapat disimpulkan bahwa GDP yang baik akan diikuti oleh IQ nasional yang tinggi, karena GDP sebagai suatu indikator keberhasilan ekonomi mengindikasikan bahwa semakin tinggi GDP suatu negara semakin makmur negara tersebut. Negara yang makmur dan dapat memenuhi kebutuhannya, lebih mampu menyediakan asupan gizi yang berkualitas bagi rakyatnya. Sehingga generasi yang muncul pada negara yang memiliki GDP tinggi adalah generasi yang terpenuhi kualitas asupan gizi nya, yang secara biologis akan meningkatkan kualitas generasi tersebut. Hal ini mungkin dapat menjelaskan keterkaitan IQ nasional yang tinggi dengan GDP.

Penjelasan lain mengenai tingginya keterkaitan antara IQ nasional dengan GDP adalah, bahwa IQ nasional yang tinggi mengindikasikan kecerdasan yang tinggi dari populasi suatu negara. Bangsa yang terdiri dari masyarakat yang cerdas diindikasikan lebih mampu mengatur urusan ekonomi negaranya lebih cerdas dibandingkan dibandingkan negara lain. Keberhasilan mengatur ekonomi negara dalam hal ini berkaitan dengan IQ nasional suatu bangsa.

Hasil nilai koefisien korelasi antara IQ Nasional dengan Indeks persepsi korupsi didapatkan nilai koefisien korelasi sebesar $r=0,919$ ( $p<0,01)$ dengan sumbangan efektif sebesar $84,4 \%\left(r^{2}=0,844\right)$. Hasil ini juga mengindikasikan bahwa terdapat keeratan hubungan positif yang sangat signifikan antara IQ nasional dengan indeks persepsi korupsi. Artinya, semakin tinggi IQ Nasional yang didapatkan, semakin tinggi pula skor Indeks persepsi korupsi (semakin tinggi skor menandakan Negara tersebut dipersepsikan semakin bersih dari korupsi), begitupula sebaliknya.

Keterkaitan antara IQ nasional dengan indeks persepsi korupsi berkorelasi amat tinggi dengan sumbangan efektif antar varians sebesar $84,4 \%$. Secara teoritis, IQ nasional yang tinggi yang merupakan indikasi tingginnya kecerdasan rata-rata serta kepemilikan sumber daya manusia yang berkualitas di suatu negara merupakan hal yang penting dalam tata kelola pemerintah dan ketaatan dari masyarakat untuk tidak terlibat korupsi. Masyarakat yang cerdas, mengetahui bahwa korupsi merupakan hal yang amat merugikan bagi bangsa dan negaranya, sehingga mereka menghindari melakukan korupsi. 
44 | Indeks Persepsi Korupsi

\section{KESIMPULAN}

Walaupun sederhana, penelitian ini mampu melihat secara nyata keterkaitan antara IQ nasional dengan GDP dan indeks persepsi korupsi di antara negara-negara Asia Tenggara. Keterkaitan antara IQ nasional dan GDP memperkuat hasil penelitian lain yang menunjukkan terdapat korelasi positif antara IQ nasional dengan indikator ekonomi suatu bangsa.

Penelitian ini hanya mampu membuktikan secara empris bahwa IQ nasional juga berkorelasi amat tinggi dengan indeks persepsi korupsi di antara negara-negara Asia Tenggara. Keterkaitan antara IQ nasional dengan indeks persepsi korupsi menarik untuk dijelaskan dengan penelitian-penelitian lebih lanjut yang lebih fokus melihat faktor-faktor lain yang mungkin terlibat dalam keterkaitan antara IQ nasional dan indeks persepsi korupsi. Sehingga keterkaitan antara IQ nasional dengan indeks persepsi korupsi dapat dijelaskan lebih detail. Namun, melalui hasil penelitian ini, secara sederhana, dapat disimpulkan bahwa negara yang memiliki populasi masyarakat lebih cerdas memiliki kemungkinan untuk korupsi semakin kecil, dan sebaliknya negara yang memiliki populasi kurang cerdas makin rentan untuk terjerat masalah korupsi.

\section{DAFTAR PUSTAKA}

Bernstein, D. A., Stewart, C. A., Roy, E. J., \& Srull, T. K. (1994). Psychology. Third edition. Boston: Houghton Mifflin Company.

Eggen, P., \& Kauchak, D. (1997). Educational psychology, windows on classroom. Third edition. Upper Saddle River, New Jersey: Prentice-Hall, Inc.

Gardner, H., Kornhaber, M. L., \& Wake, W. K. (1996). Inteligence : Multiple perspectives, USA: Wadsworth.

Kanazawa, S. (2006). IQ and the wealth of states [Versi Elektronik]. Intelligence, 34, 593-600.

Lynn, R., Meisenberg, G., Mikk, J., \& Williams, A. (2007). National IQs predict differences in scholastic achievement in 67 countries [Versi Elektronik]. J.biosoc.Sci, 39, 861-874. doi:10.1017/S0021932007001964.

Mahadana Learning. (2008). Gross domestic product. Didapatkan 1 Juni 2009 dari http://www.mahadanalearning.com/index2.php?option=com content\&do pdf=1\&id=106

Passer. M., \& Smith. R. (2007). Psychology: The science of mind and behavior. $3^{\text {rd }}$ ed. New York: McGraw-Hill.

Quah, J. S. T. (2003). Causes and Consequences of Corruption in Southeast Asia: A Comparative Analysis of Indonesia, the Philippines and Thailand [Versi Elektronik]. Asian Journal Of Public Administration, 25(2), 235266.

Rao, R. R., Jani, R., \& Sanjivee, P. (2008). Health, quality of life and GDP: An ASEAN experience [Versi Elektronik]. Asian Social Science, 4(4), 70-76.

Shatz, S. M. (2007). IQ and fertility: A cross-national study [Versi Elektronik]. Intelligence, 36(2), 109-111.

Tranparency International. (2003). Corruption Perceptions Index 2003. Didapatkan 6 Februari 2010 dari http://www.transparency.org/cpi/index.html\#cpi

Vanhanen, T. (2004). Human Development Related to Human Diversity (National IQ). Manuskrip. Tidak diterbitkan. University Of Helsinki di Finlandia. 